\title{
The Path Finding of Emerging Festival Sports Development in Minority Areas*
}

\author{
Jun Wang \\ Institute of Physical Education \\ Yunnan Agricultural University \\ Kunming, China
}

\author{
$\mathrm{Ni} \mathrm{Lu}$ \\ Institute of Physical Education \\ Yunnan Agricultural University \\ Kunming, China
}

\author{
Jianke Yang** \\ Institute of Physical Education \\ Yunnan Agricultural University \\ Kunming, China \\ **Corresponding Author
}

\begin{abstract}
Festival sports, as an important part of the festival, are concentrated expression of the national culture. Although the time of the festival is short, it is very important to the society and the influence of the people. In the context of the sports industry development, this article takes the Yunnan Cubilose Festival as a case study to analyze the association and similarities and differences between minority festival sports and emerging festival sports while analyzing the development of emerging festival sports. The author hopes to explore a development path of the new festival sports on the basis of satisfying people's needs and creating local cultural brands, so as to enhance China's cultural soft power, protect ethnic cultural diversity, and elevate national self-confidence and pride, promoting growth of related socio-economy.
\end{abstract}

Keywords-festival sports; emerging festival sports; Cubilose Festival; swallow cave; path finding

\section{INTRODUCTION}

In human society, festivals are rooted in the spiritual production activities of and are the intersection of social politics, economy, culture, and social relations. In a sense, festivals are the epitome of society and a king of lifestyle coexisting with group life while people seek to pull out of unitary life and pursue herd life. The reason why festival sports activities can trigger people's excitement is because this emotional experience arouses people's dependence on the collectiveness, which maintains the unity of society. With the continuous deepening of China's reform and opening up, many new theories and ideas have been put forward in the economic theory circle centering on the reform direction and strategic decisions. After advocating the marketization of resource allocation and the liberalization of market competition, all localities began to promote the image of the city with purpose, promote the development of tourism, and the tertiary industry, hastening the rapid development of a new thing-emerging

*Fund Project: General Project of National Social Science Fund (14BTY082). festival sports. At present, there are more and more industries involved in sports activities in China. Especially in recent years, the number and scale of emerging festival sports activities have been growing explosively with richer and richer theme. During the process, we can see two other features that traditional culture and modern ideas have mingled with each other, and the industrialization trend has become apparent. Meanwhile, festive brands are becoming more mature under the development of inheriting history and creating future accompanied by more prominent activity theme. During the period of 2014, the author carried out field research on the activities, cultural connotations, and living conditions of the Bird's Nest Festival of Jianshui County in Yunnan Province two times subsequently. From 2014 to 2017, the author participated in the sports and cultural activities of the Cubilose Festival for many times. Based on the existing research results, the author tries to re-examine the connection between ethnic minority festival sports and emerging festival sports through the perspective of festival culture, and hopes to draw some of new points that serve to not only expand the development of festival industries but also adapt to traditional national sports innovation. From the point of view, the development path of new festival sports can be explored.

\section{THE PATTERN OF EMERGING FESTIVE SPORTS ACTIVITIES}

With the development of local economic and social construction in our country, new festival sports activities have also been driven by the festival economy. Judging from a scientific attitude, various emerging festival events in China have more or less problems, and there are still no absolutely independent and complete festival sports. In recent years, there has been a great difference in the quality of emerging festival activities across China. Judging from the pattern of activities, these festival activities are mainly divided into three modes: government-led, government-assisted enterprises, and civil voluntary organizations. The first one is government-led model. As a new thing in the development of the times, the growth 
and development of emerging festive sports activities can not be separated from the government's policies and financial support. In this model, the government plays a very important role. The government assumes the dual responsibility of hosting and undertaking the activity. It not only provides policy basis and guidance for the development of the event, but also provides venues, personnel organization and services for festivals. It also determines the theme, form goals, and evaluation systems of such activities. The second one is the mode that the government assists enterprises to undertake and it is a common activity pattern in recent years. Instead of fully reflecting the government's actions and wishes, this model means that the activity will be organized and progressed by companies or organizations with the support of the government. This mode of organizing has greatly reduced the financial burden on the government, and at the same time offers the selfpromotional brand effect to the company. In the governmentassisted enterprise model, the government provides policy support and guidance and supervision, which reflects its management, and the company or organization undertakes specific things of part of the activities, which shows its execution. The win-win development model is more in line with market demand. The third model is civil spontaneous organization. The form of this activity is initiated by the civil people themselves. Different from the former two modes, the emerging festive sports activities that are spontaneously held by the people entirely come from personal or social organizations. They have such characteristics of small scale, low use of funds and narrow influence etc..

\section{SOME PROBLEMS IN THE DEVELOPMENT OF EMERGING FESTIVAL SPORTS}

Although a lot of achievements have been made in the development of many emerging festival sports in China, there are also a series of problems such as inaccurate positioning of sports, lack of cultural connotation, single operation mode, and weak people's foundation etc,. Among these issues, there are two main points that are common and universal:

Organizational disorder often occurs. Emerging festive sports activities in many areas in China have shown a certain degree of disorder from the creativity to the organization. There are no unified management institutions and organizational forms. What's worse, this disorder has become more and more apparent with the rise of new sporting events in China in recent years. From the point of management institutions, the phenomenon of chaos in emerging festive sports shows no specific organization and management department, and it shows some randomness and lack of professionalism in the process of organizing activities. At present, in China, for most emerging festive sports activities, local governments decide to organize them on the basis of local economic development and even the achievements of local governments. So, it is inevitable that there will be insufficient preparations or waste of resources.

Emerging festive sports theme choices are similar and the positions are inaccurate. Many of the emerging festival sports activities in China have not conducted detailed market surveys. Before the launch of the event, the time and place required for the research as well as the event items etc. are not taken into consideration. The subjectivity and blindness of the research activities lead to the duplication of the festival sports activities and unreasonable distribution of time and space. In addition, from the national level, there is a protruding problem that the activity tends to follow the fashion. As the marathon project has boomed in recent years, marathon activities have blossomed all over the country in the name of the National Fitness Festival. The disorderly development of the marathon project also brought about a series of social problems such as sudden death of participants and urban traffic. At the same time, we also noticed that many of China's emerging festival sports activities are like to use the concept of "international" in the process of hosting the festival. This concept of moving to large regions is itself an indication of inaccurate positioning.

With the emerging festive sports activities flocking together, there are problems of unclear cultural connotation and weak people's foundation. In recent years, the short-lived phenomenon of emerging festive sports activities has occurred in China's festive events. After the first session of a certain emerging festival sports event in some regions, it is difficult to see the second or third one.And maybe only after some years, can we see the second session. The causes of the short-lived phenomena of this emerging festive sports event are all different, but in the final analysis, the main reason for this phenomenon is the lack of clear cultural connotation and weak people's foundation.

\section{THE DIFFERENTIATION OF EMERGING SPORTS DEVELOPMENT PATH SELECTION}

The unique nature of man lies in that he must live in the material world, which is shared by all organisms according to his own intentions. In recent years, new sports projects have been popularized through the development of festivals. This kind of sports activity satisfies the ever-changing consumer demand and novelty-seeking psychology, which demands the activity to innovate but not blindly imitate. As a new thing, the greatest development advantage of emerging festival sports lies in its variability. Withdrawing from the shackles of changing form, under the inevitable requirements of differentiated development, emerging festival sports should always pay attention to individuality and actively take the path of differentiated progress in the path of development.

Pay attention to originality. With the development and prosperity of the social sports culture in China, great progress has been made in the construction of the sports culture industry and sports culture cause in China. The new festival sports activity is not only a kind of cultural activity that can bring significant economic benefits, but also means regional construction and self-image promotion as well as enriches people's cultural experience and cultural life. Nowadays, there are similar or even same defects in the themes and activity contents of many new festival sports, which gradually deplete people's expectations for new festival activities. Innovation is an essential factor in the sports activities of the new festival, and the breakthrough point of innovation lies in the local characteristics and advantages of resources. The local characteristic and advantageous resources are cannot be duplicated. The promotion and utilization of natural resources or social cultural resources will play an important role in the 
development of new festivals sports activities. As the Jianshui Cubilose Festival, it puts "climbing rock" into festival activities with the aid of its own cave conditions, which endow the festival culture with more connotations. It can be seen that in the development of emerging festival sports, it is necessary to dig out contents and innovate forms in accordance with local featured resources in the process of developing festival activities.

To draw on the development experience from traditional ethnic festival sports. The development of emerging festival sports should be dominated by the government, linked together by enterprises and they are supposed to learn from the pattern of national festival sports development as well as pay attention to the use of festival symbols to form the consciousness of the people. In addition, combined with the characteristics of the project, we should strive for multi industry coupling when the government helps. In the meantime, the nutrition from the development model of the convention and exhibition industry can be extracted as a new sport phenomenon and marketing communication method. Emerging festival sports have their own characteristics and advantages in their emergence and development and they have a good function of cultural communication. Organizers can use the platform function of festival economy to attract more enterprises to participate and even pay for such events. For emerging festival sports, if they want to continue to develop steadily, it is necessary to constantly create new content with the changes of the times so as to fundamentally arouse the self-consciousness and spontaneity of the people and gradually get out of the government's lead. The commercial nature of emerging festival sports has determined that the basic masses foundations are much weaker than those of national festival sports, but emerging festival sports are an innovation in the process of modern market economy development. To make this kind of innovation acceptable in all aspects, stimulating the interest and consciousness of the masses is one of the paths that emerging festival sports can live forever.

\section{DifFERENTIAL ROAD SHOULD BE FOLLOWED ACCORDING TO LOCAL CONDITIONS}

The future development of emerging festival sports is diversified, but it should be noted that in the process of development, it is necessary to regard regional advantages, draw on the characteristics of the nation, and multi-cultural exchange to achieve industrial development. The new festival sports should take location advantage to find the difference between the local and other regions.

To realize the differential development of the new festival sports by using the differentiated resources. Nationality is a stable community formed by four basic characteristics, which are common language, common area, common economic life and common psychological quality displayed on the common national cultural characteristics. National resources are precious wealth, and things with national characteristics are more acceptable to the world. Ethnic resources themselves are a kind of differentiated resources. New festivals sports are combined with local minorities in both form and content, forming obvious characteristics, which is conducive to industrial development. In addition, emerging festival sports should also pay attention to the combine with traditional culture, religious beliefs, and history in content and form. Emerging festival sports themselves are a kind of cultural phenomenon. They have the characteristics of cultural activities. For cultural activities, as long as they have different cultural characteristics from other places, they can be combined with emerging festival sports.

\section{CONCLUSION}

The rise of emerging festival sports in our country has injected new vitality into the development of the sports industry. However, on the whole, it is still in the primary stage of development. The study of emerging festive sports is still immature. Faced with the vigorous development of the new festival sports industry practice, this lack of understanding is very unfavorable to its development. It will lead to the development deviation of new festival sports and the emergence of homogenization, assimilation and other blind obedience phenomenon. In terms of project settings, they still remain in pursuit of short-term benefits of surface entertainment and leisure activities, and do not make much fuss about deep creation and creativity. This will bring the development of new festival sports industrialization. Judging from the current operating mechanism in China, there are still many places in the system that is not in line with its development. The construction of the system lags behind the reality of development. Besides that, there is a lack of coordination between the various sectors and organizations such as sports culture, finance, and science and technology, leading a series of severely institutional problems, such as the unclear responsibilities and rights, and the separation of management from execution. The development of emerging festival sports in China is only just beginning. As the development of a creative sports industry, only the training force of related talents is strengthened and a good social environment is created, can emerging festival sports develop fundamentally.

\section{REFERENCES}

[1] Prentice, R.\& V. Anderson. Festival as Creative Destination [J]. Annals of Tourism Reseaeh, 2003 (I): 7-30

[2] Jingwen Zhong. An Introduction to Folklore[M]. Shanghai: Shanghai Literature and Art Publishing House, 1998: 62.

[3] [U.S.A] W. F. Orgrim writes, Xiaoyi Wang, Yuguo Chen translates. Social changes - about the nature of culture and innateness [M]. Hangzhou: Zhejiang people's publishing house, 1989: 144.

[4] Jianhua Fan. On Festival Culture and Festival Industry[J].Academic Reseach, 2011, (02): 13.

[5] [U.S.A] Ralph Linton writes, Minmei Yu, Xuejing Chen translate. The Cultural Background of Personality: A Study of the Relationship among Culture, Society and Individuals[M] Guilin: Guangxi Normal University Press, 2007: 99.

[6] [U.S.A] Philip Kotler writes. Marketing Management[M]. Shanghai: Shanghai People Press, 200: 35.

[7] Quinn B. Changing festival places: Insights Irom Ualway. Social Cultural Ueography, 2005, 6(2): 237-252.

[8] Ekman A. The revival of cultural celebrations in regional Sweden Aspects of tradition and transition. Sociologic Ruralis 1999.39(3): 280293. 
[9] [U.S.A] Marshall Sallins writes, Bingxiang Zhao translates. Culture and Practical Reason ·Preface [M] Shanghai: Shanghai People Press, 2002: 2.

[10] [Russia] Stalin writes, Baohua Cao, Anqing Mao translate. Ethnic issues and Leninism [M]. Beijing: People's Publishing House, 1951: 22. 